\title{
INTERNET CENSORSHIP BY LAW: A CHALLENGE TO THE CONSTITUTIONAL RIGHT TO FREEDOM OF EXPRESSION IN THAILAND
}

\author{
Jompon Pitaksantayothin*
}

\begin{abstract}
In Thailand, at present, content on the Internet is subject to a legal regulatory framework. The Ministry of Information and Communication Technology (MICT) takes a leading role in enforcing the Computer-Related Crime Act 2007 to censor content on the Internet which is deemed 'illegal'. In this article, it is contended that the legal regulation of Internet content which Thailand adopts is problematic in several aspects. This could pose a serious threat to the constitutional right to freedom of expression of Internet users in Thailand.
\end{abstract}

Keywords: Internet censorship, freedom of expression, Thailand.

\section{Introduction}

In Thailand, the right to freedom of expression is guaranteed by the Thai Constitution 2007. ${ }^{1}$ Despite the constitutional guarantee, the Thai government has been notoriously imposing restrictions on freedom of expression on the Internet. In 2007, the Computer-Related Crime Act was passed to legitimize the Ministry of Information and Communication Technology (MICT)'s implementation of Internet censorship. However, this article argues that the legal regulatory approach that Thailand has taken seriously lacks transparency. This

\footnotetext{
Lecturer, School of Law, University of the Thai Chamber of Commerce, Bangkok, Thailand On May 22, 2014, the Royal Thai Army staged a coup d'état in Thailand. The junta called National Council for Peace and Order (NCPO) has taken over control of the country since then. Under the NCPO Decree No.11/2557, the Thai Constitution 2007 was repealed on May 22, 2014. It is Important to note that, this paper was submitted before the 2014 coup d'état and the repeal of the Thai Constitution 2007. However, as the right to freedom of expression is a universal and principal human right, the author of this article strongly believes that the right to freedom of expression provision will appear in the forthcoming Thai constitution. Thus, when Thailand has the new constitution, the main arguments against Internet censorship and legal principles explained in this article will remain unchanged.
} 
could pose a serious threat to the right to freedom of expression of Internet users in Thailand.

This article begins the discussion with a brief account on the importance of freedom of expression and how censorship has subversive effects on the value of freedom of expression. Then, it will examine the situation and the process of Internet censorship by law in Thailand. Finally, it will give comments on concerns of the negative impacts that Internet censorship has on freedom of expression of Internet users in Thailand.

\section{THE RIGHT TO FREEDOM OF EXPRESSION}

The right to freedom of expression has long been universally recognized as an important human right. At international level, it is enshrined in several key human rights instruments, such as Article 19 of the Universal Declaration of Human Rights (UDHR) ${ }^{2}$ and Article 19 of the International Covenant on Civil and Political Rights (ICCPR). ${ }^{3}$ At national level, it is guaranteed by national constitutions of a number of countries across the globe, for example, the First Amendment to the US Constitution (the protection of free speech), Article 21 of the Constitution of the Republic of Korea, Article 10 of the Constitution of Malaysia, Section 16 of the Constitution of the Republic of South Africa, Article 5 of Basic Law for the Federal Republic of Germany, and Article 5 of the Constitution of Brazil.

In Thailand, the right to freedom of expression is guaranteed by the first paragraph of Section 45 of the Thai Constitution 2007. It reads:

A person shall enjoy the liberty to express his or her opinion, make speeches, write, print, publicize, and make expression by other means ...

\footnotetext{
Article 19 of the UDHR reads 'Everyone has the right to freedom of opinion and expression; this right includes freedom to hold opinions without interference and to seek, receive and impart information and ideas through any media and regardless of frontiers'.

3 Article 19 of the ICCPR provides ' 1 . Everyone shall have the right to hold opinions without interference. 2. Everyone shall have the right to freedom of expression; this right shall include freedom to seek, receive and impart information and ideas of all kinds, regardless of frontiers, either orally, in writing or in print, in the form of art, or through any other media of his choice. 3 . The exercise of the rights provided for in paragraph 2 of this article carries with it special duties and responsibilities...'
} 
In essence, the guarantee of the right to freedom of expression ensures that individuals are entitled to the right of imparting, seeking and receiving information, opinions and ideas without unjustifiable, unnecessary and excessive restrictions imposed by the states. This notion is applicable to the exercise of the right to freedom of expression both in the 'real world' and cyberspace.

At this point, this article will gives a brief account on three wellknown theoretical explanations which underpin the importance of freedom of expression, and points out how censorship has negative impacts on the value of freedom of expression. The first one is the argument from truth, proposed by John Stuart Mill, a famous English philosopher. According to Mill, freedom of expression allows different opinions and ideas to compete each other freely in an open discussion. The competition would eventually lead to the discovery of truth of a particular issue. ${ }^{4}$ Furthermore, much like humans, the states are 'fallible and prone to error'; thus, it is always possible for the states to censor opinions and ideas which may turn out to be 'true'. ${ }^{5}$ In other words, the 'assumption of infallibility' of the state may prevent society to reach the ultimate truth. ${ }^{6}$

The second explanation is the argument from democracy. Alexander Meiklejohn, a notable American philosopher and free speech advocate, posits that the right to freedom of expression is crucial for well-functioning democracy. It allows all essential information relating to political choices accessible to the electorate. This would, in turn, make it possible for the voters to fully acknowledge pertinent issues and, perhaps most importantly, make intelligent voting. ${ }^{7}$ Put differently, censorship would make it difficult for voters to access full information relating to political issues; and, as a result, they may not be able to make wise voting.

The third theory is the argument from autonomy and self-fulfillment. Thomas Scanlon, a well-known American philosopher, points out that, as to maintain individual autonomy, a person should solely rely

\footnotetext{
Barendt, E., Freedom of Speech ( $2^{\text {nd }}$ ed.), (Oxford University Press, Oxford, 2005), p.7

Schauer, F., Free Speech : A Philosophical Enquiry, (Cambridge University Press, Cambridge, 1982), p.34

6 Mill, J. S., On Liberty, Bromwich, D. and Kateb, G. (eds.), (Yale University Press, New Haven, 2003), p.88

7 Ibid., pp.36-38.
} 
on 'his own canons of rationality' to reach his own non-influenced judgment for what he should follow. ${ }^{8}$ Freedom of expression permits a person to access a full range of various ideas and opinions, and base on them to make an autonomous judgment. Censorship allows an external interference to judge for a person that the censored ideas or opinions are not worth hearing; thus his individual autonomy is, in effect, denied. ${ }^{9}$ Individual autonomy is a crucial tool for a person to achieve self-fulfillment, i.e. the growth of one's personality in relation to mental and intellectual abilities to reach full potential. ${ }^{10}$ Given this view, censorship prevents a person to access to full range of ideas and opinions, and ponder upon them to make a judgment (the exercise of individual autonomy); as a consequence, he would lose his opportunity to sharpen his critical thinking skills and develop mental ability.

\section{Censorship and the Restriction of Freedom of Expression}

As discussed above, censorship undermines the value of freedom of expression to a great extent. However, this does not mean that the right to freedom of expression is absolute. As commonly accepted, in the circumstances where compelling public interests are at risk and it is necessary to restrict freedom of expression to protect such interests, the states may be permitted to implement censorship. The second paragraph of Article 19 of the ICCPR makes it clear that the states may resort censorship to safeguard certain public interests. It reads:

It may therefore be subject to certain restrictions, but these shall only be such as are provided by law and are necessary: (a) For respect of the rights or reputations of others; (b) For the protection of national security or of public order (ordre public), or of public health or morals.

Similarly, the second paragraph of Section 45 of the Thai Constitution 2007 permits the Thai authorities to impose limitation on the right

\footnotetext{
Scanlon, T., 'A Theory of Freedom of Expression', in Dworkin, R. (ed.), The Philosophy of Law, (Oxford University Press, London, 1977), p.163.

9 Ibid., p.164

${ }^{10}$ Redish, M. H., 'The Value of Free Speech', (1982) University of Pennsylvania Law Review, 130(3), pp.591-645, p.593.
} 
to freedom of expression, on the condition that such limitation has a legal basis and aims to protect certain public interests. It provides:

The restriction on liberty under paragraph one shall not be imposed except by virtue of the law specially enacted for the purpose of maintaining the security of State, protecting the rights, liberties, dignity, reputation, family or privacy rights of other persons, maintaining public order or good morals or preventing or halting deterioration of the mind or health of the public ...

\section{The Situation of Internet Censorship by Law in Thailand}

There is evidence showing that the Thai authorities began to implement Internet censorship as early as $2002 .{ }^{11}$ In 2002, the Thai police ordered the ISPs in Thailand to block access to the website of Patani United Liberation Organization (PULO), www.pulo.org. ${ }^{12}$ In the same year, the responsibility to implement Internet censorship was transferred from the Thai police to the MICT. The MICT employed the same strategy as the Thai police did, by ordering the Thai ISPs to block websites which the MICT regarded as illegal websites. Failing to adhere to the MICT's orders, the ISPs could be face penalties in the form of license suspension, revocation or the denial of renewal of license. In 2003, over 100 websites were blocked in 2003; and in 2004, approximately 1,247 websites were made inaccessible. ${ }^{13}$ As of May 2006, 2,475 websites were censored. ${ }^{14}$ However, the number of blocked websites rose dramatically to 13,435 in January $2006 .{ }^{15}$ In addition, there was an unspecified number of websites that were blocked secretly by the Communication Authority of Thailand (CAT) at Thailand's International Gateway. ${ }^{16}$ Interestingly,

\footnotetext{
${ }^{11}$ Privacy International and the GreenNet Educational Trust, Silenced - An International Report on Censorship and Control of the Internet, (Setline Data Ltd, London, 2003), p.62

${ }^{12}$ Ibid.

${ }_{13}$ Paireepairit, I., Internet Censorship in Thailand, (2008) a Thesis submitted for a Degree of Master of Science in Information Management, the University of Sheffield, p.35.

${ }^{14}$ Freedom Against Censorship Thailand (FACT), http://facthai.wordpress.com/2006/12/06/ analysis-mict-blocklist-26-may-2006/, accessed 13 ${ }^{\text {th }}$ August 2013.

${ }^{15}$ Freedom Against Censorship Thailand (FACT), http://facthai.wordpress.com/2007/01/15/ thai-website-censorship-jumps-by-more-than-500-since-coup//, accessed $13^{\text {th }}$ August 2013.

16 Ibid.
} 
the Internet censorship during this period was implemented without a legal basis since, at that time, there was no legislation allowing the Thai police and the MICT to force the ISPs to censor Internet content. Furthermore, the legality of the blocked websites was not considered by the competent Thai courts.

In 2007, The National Legislative Assembly of Thailand, a legislative body set up by the junta after the 2006 Coup d'etat, passed a new law, the Computer-Related Crime Act BE 2550. Section 20 of this legislation gives legal power to the MICT to censor content on the Internet. It reads:

In the case where an offence committed under this Act involves disseminating computer data that could undermine national security as prescribed in the Criminal Code, or is against the public peace or good morals, the competent official, with the Minister's approval, may submit a request with evidence to the competent court for an order to suspend/block the dissemination of such computer data.

This means that after Computer-Related Crime Act BE 2550 came into force on July 18, 2007, the MICT's implementation of Internet censorship has become legitimate. The research conducted by Research Team on 'Impact of the Computer-Related Crime Act 2007 and State Policies on the Right to Freedom of Expression ${ }^{17}{ }^{17}$ 2012 reveals that, from July 2007 to 2011, the MICT used its power given by Section 20 to block approximately 81,213 URLs. ${ }^{18}$ More recently, according to iLaw - an NGO website which reports issues relating law and the Internet in Thailand, in 2012 alone, 21,248 websites were blocked by the MICT; and in 2013, 5,369 websites

17 The Research Team is supported by iLaw (http://ilaw.or.th/), an NGO which aim to give legal knowledge to the public in Thailand. It is comprised of two legal academics (Sawatree Suksri and Siriphon Kusonsinwut) and five free speech activists (Orapin Yingyongpathana, Danuch Wallikul, Yingcheep Atchanont, Thanakrit Piammongkol and Tewson Seeoun).

18 Research Team, Impact of the Computer-Related Crime Act 2007 and State Policies on the Right to Freedom of Expression', http://ilaw.or.th/sites/default/files/ ComputerCrimeResearch.pdf, accessed 14 ${ }^{\text {th }}$ August 2013, p.14 
were blocked. ${ }^{19}$ (It should be noted that after the 2014 coup d'état on May 22, 2014, approximately 219 websites deemed a threat to the country's stability were blocked. ${ }^{20}$ )

\section{The Process of Website-Blocking ${ }^{21}$}

The process of website-blocking is not available for the public in Thailand. However, during the course of the author's PhD research at Leeds University, the author had a chance to interview representatives from organizations involved in the implementation of Internet censorship in Thailand, i.e. the MICT, ${ }^{22}$ Technological Crime Suppression Division (TCSD) of Royal Thai Police ${ }^{23}$ and TOT ISP (one of the biggest ISPs in Thailand). ${ }^{24}$ Based on information deriving from the interviews, the overall picture of the process of website-blocking can be illustrated as follows:

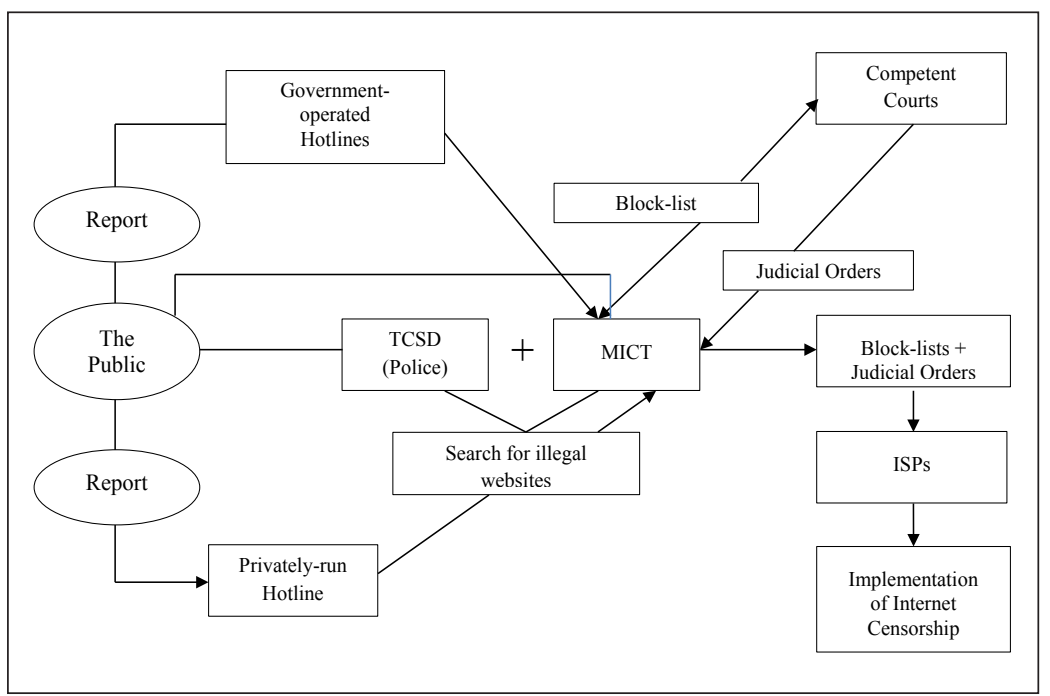

9 iLaw, http://freedom.ilaw.or.th/node/97, accessed 6 ${ }^{\text {th }}$ July 2014.

20 https://za.news.yahoo.com/facebook-back-thailand-still-blocking-219-sitescoup-033607503.html, accessed $6^{\text {th }}$ July 2014.

21 It should be noted that the process of website-blocking described here is the process that was implemented before the 2014 coup d'état took place. Unfortunately, there is no information about the website-blocking process after the 2014 coup d'état available.

22 Interview with the MICT, $3^{\text {rd }}$ May 2011.

23 Interview with the TCSD, $19^{\text {th }}$ April 2011.

24 Interview with TOT, $27^{\text {th }}$ April 2011. 
The process of Internet censorship begins with the MICT making a block-list. The MICT and the TCSD have a special department whose main duty is to search for illegal websites. The search is implemented by software, which is specially developed for this purpose and for governmental use only. ${ }^{25}$ The URLs of the illegal websites from the special searching department are passed on to the MICT to make a final decision about what URLs should be blocked. The majority of illegal website URLs on the block-lists come directly from the special searching department, whereas the illegal website URLs reported by the public (through government-run and privately-operated hotlines) account for very little percentage of the URLs on the block-lists. The MICT has never published any official report on the number and the details of the URLs on the block-lists.

The MICT will submit the block-list, together with a request for a judicial order (which is approved by the MICT Minister), to a competent court. When the court issues a judicial order permitting Internet censorship, the judicial order and the block-list will be passed on to all ISPs in Thailand by the MICT. Subsequently, the ISPs implement website-blocking by inputting the URLs on the block-list onto special software (server-based filtering). As a result, when users attempt to access a particular blocked website, they will be diverted to a screenshot stating that the website has been blocked by the MICT.

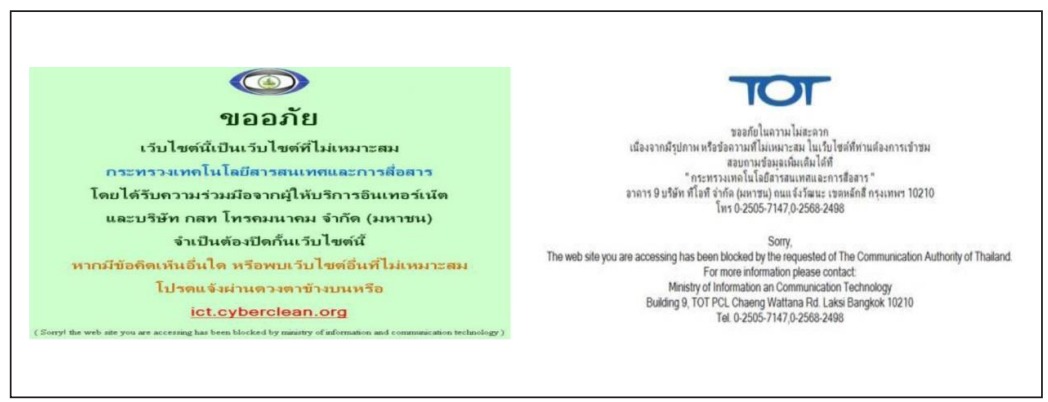

Picture 1: the screenshots inform that the website is blocked by the MICT (on the left) and by TOT ISP (on the right). These screenshots were used until the 2014 coup d'état.

$25 \quad$ The interviewees did not reveal the technology and how the searching software works. 


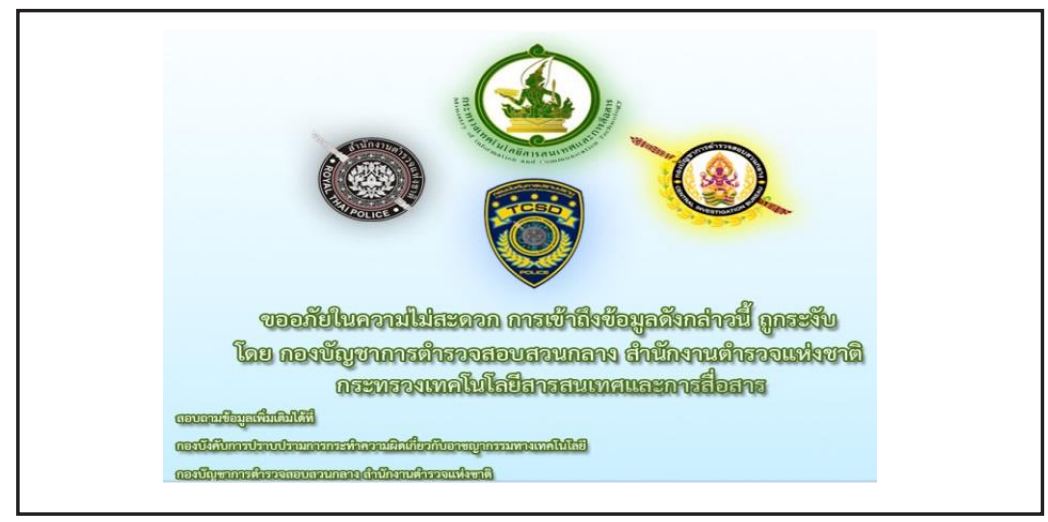

Picture 2: the screenshot informs that the website is blocked by the MICT, Royal Thai Police, Central Investigation Bureau and Technology Crime Suppression Division. This screenshot has been used since May 2014 (after the 2014 coup d'état).

\section{Internet Censorship and its Implication on the Right to Freedom of Expression}

In this section, this article discusses the negative impacts of the Internet censorship by law and its implementation on the constitutional right to freedom of expression of Internet users in Thailand.

First, it is without doubt that state censorship is a restriction of the right to freedom of expression. Although, as discussed above, the right to freedom of expression is not absolute, the Internet censorship should be implemented only if it is necessary to protect certain important public interests, such as national security, public health or the legitimate rights of others. However, as one can see from the statistical data above, the number of blocked URLs dramatically increases every year. It is doubtful whether the Internet censorship is implemented as a necessary measure to protect certain compelling interests, or as a tool to silence Internet users. However, as the information regarding the censored and the grounds on which they are censored are not made available for the public, it is extremely difficult to for the public to check whether the Internet censorship is implemented properly and according to the law. Obviously, this problem is caused by the lack of transparency of the implementation of Internet censorship. 
Second, given the sheer number of potentially illegal websites the Internet, it is impossible for the MICT to censor all of them. In practice, the MICT authorities selectively block only some potentially illegal websites. ${ }^{26}$ This means that only certain specific illegal websites are blocked whilst a number of illegal websites, which may have the same or similar content, are still on the Internet. This raises questions as to what criteria the MICT use to select those potentially illegal websites, and whether they have bias against, or in favour of, certain websites.

Third, Section 20 requires the MICT to request a judicial order from a competent court before implementing Internet censorship. This means that, ultimately, it is a court - being a judicial body, rather than the MICT, which is a non-judicial body - that decides whether the website or content in question is illegal and should be censored. This can be considered as a merit of the Thai regulatory system. However, the main criticism of the role of the Thai courts under the current Thai regulatory framework is that the courts may not spend sufficient time to consider the legality of URLs on the block-lists. The Research Team remarks that, in most cases, 'the courts take an extremely short period of time (within a day) to look at the URLs [on the block-lists]' ${ }^{27}$ Given that there are hundreds or even thousands of URLs on the block-lists, it is doubtful whether the courts have scrutinised those URLs thoroughly before granting an order authorizing the blocking or whether they act merely as 'a rubber stamp' for the MICT.

Fourth, the URLs on the block-lists are derived mainly from the special searching department; more significantly, the block-lists are not made available to the public. This could raise an issue of transparency. It is very difficult for the Internet users in Thailand to know what websites are blocked (unless they try to access a particular website), and on what grounds they are blocked. Given this, it could be contended that the Internet users would never be entitled to the full right to freedom of sexual expression, as their right is being secretly curtailed by the MICT.

\footnotetext{
26 Interview with the MICT, on 3rd May 2011.

27 Research Team, Impact of the Computer-Related Crime Act 2007 and State Policies on the Right to Freedom of Expression', http://ilaw.or.th/sites/default/ files/ComputerCrimeResearch.pdf, accessed 14th August 2013.
} 
Fifth, once the URLs on the block-list are rendered inaccessible, Internet users and the website owners cannot appeal against the judicial order, since Section 20 of the Computer Crime Act 2007 does not provide an opportunity to do so. However, under the current Thai regulatory framework, the only way to challenge the judicial order is to bring the case to the Thai Constitutional Court, alleging that Section 20 violates the constitutional right to freedom of expression. This act is possible because the MICT is a governmental body, which is accountable to the public. Nevertheless, there has not been an attempt by anyone to file the case to the Thai Constitutional Court until now.

Lastly, as discretionary power is in the hands of the MICT, there is no room for the ISPs, webmasters, content providers and Internet users to develop and implement their own self-regulation of sexual content on the Internet.

\section{Conclusion}

It is obvious that Internet censorship by law has subversive effects on the right to freedom of expression of Internet users in Thailand. Although the right to freedom of expression is not absolute and can be restricted by Internet censorship to protect certain compelling public interests, it is argued that the Internet censorship should be implemented only if it is necessary to achieve such goal. More importantly, its implementation should be subject to the principle of transparency which requires the authorities to make information relevant to the blocked websites available to the public. However, as examined above, the current Internet censorship in Thailand appears to lack transparency, and this still continues to pose a serious threat to the constitutional right to freedom of expression of Internet users in Thailand.

\section{References}

Barendt, E., Freedom of Speech (2 ${ }^{\text {nd }}$ ed.), (Oxford University Press, Oxford, 2005).

Freedom Against Censorship Thailand (FACT), http://facthai. wordpress.com/2006/12/06/analysis-mict-blocklist-26may-2006/, accessed $13^{\text {th }}$ August 2013. 
Freedom Against Censorship Thailand (FACT), http://facthai. wordpress.com/2007/01/15/thai-website-censorship-jumpsby-more-than-500-since-coup//, accessed $13^{\text {th }}$ August 2013.

iLaw, http://freedom.ilaw.or.th/node/97, accessed $6^{\text {th }}$ July 2014.

Mill, J. S., On Liberty, Bromwich, D. and Kateb, G. (eds.), (Yale University Press, New Haven, 2003).

Privacy International and the GreenNet Educational Trust, Silenced - An International Report on Censorship and Control of the Internet, (Setline Data Ltd, London, 2003).

Paireepairit, I., Internet Censorship in Thailand, (2008) a Thesis submitted for a Degree of Master of Science in Information Management, the University of Sheffield.

Redish, M. H., 'The Value of Free Speech', (1982) University of Pennsylvania Law Review, 130(3), pp.591-645.

Research Team, Impact of the Computer-Related Crime Act 2007 and State Policies on the Right to Freedom of Expression', http://ilaw.or.th/sites/default/files/ComputerCrimeResearch. pdf, accessed $14^{\text {th }}$ August 2013.

Scanlon, T., 'A Theory of Freedom of Expression', in Dworkin, R. (ed.), The Philosophy of Law, (Oxford University Press, London, 1977).

Schauer, F., Free Speech : A Philosophical Enquiry, (Cambridge University Press, Cambridge, 1982).

Yahoo News South Africa, https://za.news.yahoo.com/facebookback-thailand-still-blocking-219-sites-coup-033607503. html, accessed $6^{\text {th }}$ July 2014. 